\title{
The Law of Fracture Evolution of Overlying Strata and Gas Emission in Goaf under the Influence of Mining
}

\author{
Cheng Cheng, ${ }^{1}$ Xiaoyu Cheng $\left(D,{ }^{1,2}\right.$ Rui Yu, ${ }^{3}$ Wenping Yue, ${ }^{4}$ and Chao Liu ${ }^{1}$ \\ ${ }^{1}$ Xi'an University of Science and Technology, Xi'an 710054, China \\ ${ }^{2}$ China Coal Energy Research Institute Co., Ltd., Xi'an 710054, China \\ ${ }^{3}$ China Coal Huajin Group Co., Ltd., Hejin 043300, China \\ ${ }^{4}$ Shaanxi Key Laboratory of Safety and Durability of Concrete Structures, Xijing University, Xi'an 710123, China
}

Correspondence should be addressed to Xiaoyu Cheng; chengxiaoyu89@126.com

Received 15 June 2021; Revised 16 July 2021; Accepted 27 July 2021; Published 12 August 2021

Academic Editor: Feng Du

Copyright $\odot 2021$ Cheng Cheng et al. This is an open access article distributed under the Creative Commons Attribution License, which permits unrestricted use, distribution, and reproduction in any medium, provided the original work is properly cited.

\begin{abstract}
Mining is associated with poor safety due to pressure relief gas emission from the goaf during the production period. The aim of this study was to explore a case study of the Wangjialing coal mine 12322 working face in Shanxi, China, through physical simulation and field observation. The mine is characterized by overlying strata fracture in goaf during the process of working face mining. A mathematical model of gas source emission from the working face and gas migration and the finite element COMSOL software were used to simulate the law of gas migration in the region with overlying strata fissures under the influence of mining. The simulation results were used to explore the law of distribution of pressure relief gas in goaf. Rational parameters of the highlevel directional long borehole for the pressure relief gas extraction in goaf were designed based on experimental results. The results showed that the development of the region with overlying strata fissures is affected by mining. In addition, the "trapezoid platform structure" is formed after fracture areas are connected. The maximum height of the stope caving zone was between $26.8 \mathrm{~m}$ and $28.1 \mathrm{~m}$, and the maximum height of the fracture zone was approximately $110 \mathrm{~m}$. The gas concentration exhibited a saddle-shaped distribution on the cut surface of the direction of the strike. Furthermore, the gas concentration showed an overall upward trend from the intake airflow roadway to the return airflow roadway and gradually decreased after reaching the maximum. In the vertical direction, gas concentration increased with the increase in the layer, and the position of the highest point of gas concentration gradually shifted to the direction of the intake airflow roadway. Construction parameters of the high directional long borehole were designed through simulation results. After steady extraction and stable extraction, the maximum gas concentration in the upper corner of the working face was $0.49 \%$, and the maximum gas concentration in return airflow was $0.34 \%$. The findings of this study provide information on the law of fracture evolution of overlying strata and gas migration in goaf under the influence of mining. These findings provide a basis for reducing gas overlimit in the working face or return airway corner, thus improving the safety production capacity of the coal mine.
\end{abstract}

\section{Introduction}

Currently, many coal seams in China coal mines are thick continuous coal seams. The coal mines account for about $44 \%$ of the total coal reserves in China [1]. Coal is one of the main energy sources in China [2-4]. Therefore, the development of high-yield, high-efficiency, and safe mining technology for thick continuous coal seams is important to ensure the high production of coal [5]. However, the rapid development of mining technology in the coal industry results in an increase in the depth and intensity of mine mining. These features result in an increase in mine gas emission quantity. Gas release limits mine efficient mining [6-9]. The problem of high gas accumulation in the return airway corner caused by high gas emission from goaf during coal seam mining has not been fully solved $[10,11]$. Advances in mine gas control technology have significantly improved the pressure-released gas control capacity in goaf through the extraction of the high directional long borehole [12-15]. However, the buried pipe in goaf and the pressure relief gas 
drainage technology of the high borehole in coal mining are limited by the uncertainty of the gas emission law of the working face and the unclear law of the gas flow field in goaf and the unclear area of the failure of the overlying strata. High-efficiency control of gas in goaf is restricted, thus significantly affecting the safety production of coal mining. The fracture transfixion area of overburden rock under the influence of mining which leads the gas in goaf into the working face under the influence of airflow significantly affects the safety of coal mining. Therefore, there is a need to explore the distribution characteristics of the overlying strata fracture in the process of working face mining, the law of gas migration in goaf, and gas outbursts from the working face to improve the gas control capacity of mine goaf.

The caving of overlying strata forms three regions including the caving zone, fracture zone, and bending subsidence zone due to the stress effect [16]. The fracture zone is the main channel for gas transportation and seepage. Several studies have explored aspects of the fracture zone, such as empirical formula, numerical simulation, physical simulation, and field measurement. A large number of fracture development models of mining overburden have been established based on theoretical information. Palchik $[17,18]$ used the drainage method to measure the height of the fracture zone after weak overburden coal seam mining. The findings showed that the ratio of maximum height of the fracture zone to coal seam thickness increases with an increase in the interface number of overlying strata and decreases with an increase in stiffness of the immediate roof. Majdi et al. [19] determined the height of the failure region at the top of the working face using two mathematical models that were established through experimental data. Lin et al. [20] and Zhang and Wang [21] simulated the actual mining process of the working face by establishing a physical similarity model, thus analyzing the fracture evolution law of overlying strata. Furthermore, Gao et al. [22] and Wu et al. [23] simulated the collapse characteristics and fracture zone height distribution characteristics of overlying strata in goaf by establishing two-dimensional discrete element models. In addition, several studies have explored gas emission and migration in goaf based on the distribution law of the fissure zone. Yuan [24] and Danesh et al. [25] report that the law of overburden fracture evolution is correlated with gas migration in goaf. Cao and Li [26] and Liu et al. [27] explored the effect of gas drainage in goaf on gas flow in goaf and the overburden fissure zone. Whittles et al. [28] established the gas seepage model of goaf by numerical simulation and indoor experiments and explored the gas source and the path to the working face of goaf. Several studies have used these findings to explore the goaf gas treatment technology and methods. For instance, Guo et al. [29] evaluated the pressure control of coal seam horizontal drainage and developed a conceptual model on gas drainage. Moreover, Zhang et al. [30] determined the extraction situation of 29 ground boreholes in four working faces and analyzed the law of pressure relief gas extraction. Schatzel et al. [31] evaluated the dynamic influence of coal seam storage conditions and overburden structure on gas drainage in goaf during mining.
The findings from these studies have significantly improved the understanding of the fracture evolution law of mining overburden and the law of gas migration in goaf. However, most studies explore the distribution law of the fracture area in the direction of the working face, whereas the distribution law of the fissure area affected by mining in an inclined direction is not explored; therefore, it is limited in field application. In addition, the dynamic prediction model of gas emission in mining has not been fully explored. Therefore, when using these models to analyze calculations, they significantly affect the distribution of gas migration in goaf. Studies should explore the distribution range of the fissure area and the crack expansion in each area when the overlying strata in goaf are affected by mining. In addition, studies should explore ways to improve the accuracy of the gas emission prediction model in each area of the working face, ensuring accurate prediction of gas distribution in goaf to improve the effect of gas control in goaf.

This study sought to explore the evolution law of overburden fissures through a physical similarity simulation and drilling peep method. In addition, the distribution range of overlying strata fractures under the influence of mining was determined. The dynamic gas emission models of the coal wall, mining-falling coal, and remnant coal in goaf were established to improve the accuracy of gas emission prediction in goaf. Furthermore, the gas distribution and migration of goaf were tested by numerical simulation, and the gas enrichment area of goaf was explored. The results were then used to determine the reasonable drainage parameters of pressure relief gas, and the field application and effect verification were carried out. The findings of this study provide a theoretical basis for guiding mine gas accurate extraction and ensuring mine safety and efficient mining.

\section{Project Overview}

The case study mine was the Wangjialing coal mine, located in the Shanxi mine area in China. The mine has three layers of mining coal seams with an area of $119.7 \mathrm{~km}^{2}$. The minable coal seams include No. 2, No. 3, and No. 10. Currently, the main mining coal seam is the No. 2 coal seam. The main characteristics of the coal seam are low gas content and low permeability. It is a high-gas mine characterized by high yield and high efficiency. The longwall backward mining method and comprehensive mechanized top caving technology are used for this mine.

The 12322 fully comprehensive caving working face was selected as the test face. The location of the working face is shown in Figure 1. The 12322 working face was buried in approximately $400 \mathrm{~m}$ depth and had an average coal thickness of $6.2 \mathrm{~m}$, and the coal seam structure was simple. The working face roof comprised sandy mudstone and siltstone, and the working face floor comprised sandy mudstone. The working face strike length was $3300 \mathrm{~m}$, whereas the inclination length was $310 \mathrm{~m}$. The average coal seam gas content was $3.74 \mathrm{~m}^{3} / \mathrm{t}$. The averaged absolute gas emission quantity on the working surface is $9.79 \mathrm{~m}^{3} / \mathrm{min}$. The total gas content of the working face was low; however, the gas emission was 


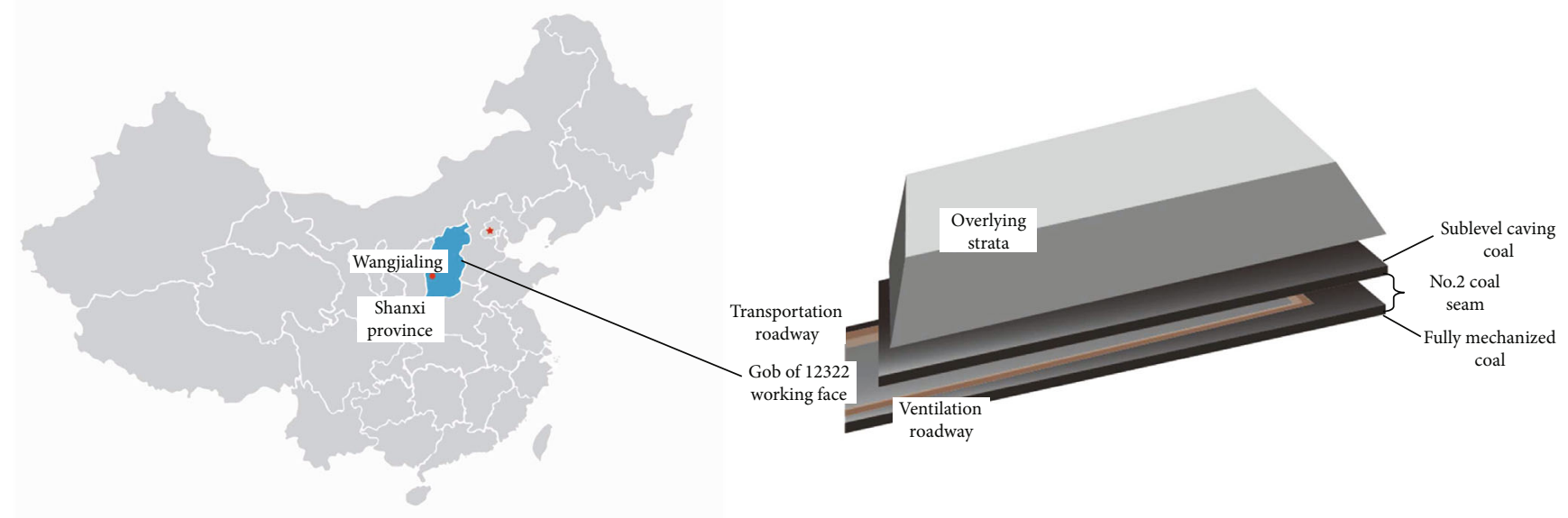

Figure 1: Distribution of coal seams in the Wangjialing coal mine.

abnormal in the mining process due to the high yield and high efficiency in the production process.

The lithology of overlying strata in coal seam mining directly affects distribution characteristics of "two-zone" fractures. Lithology characteristics and rock mechanics parameters of the overlying strata in the 12322 working face were determined based on the field drilling coring and laboratory mechanics test of the overlying strata in the 12322 working face (Figure 2).

\section{Evolution of Fracture in Overlying Strata}

\subsection{Physical Experiment of Fracture Evolution of Overlying Strata in Mining}

3.1.1. Model Design. According to geological conditions, two identical plane stress similarity simulation models were established when the ratio of geometric similarity is $1: 200$ (Figure 3). The model size was length $\times$ height $=2500 \mathrm{~mm}$ $\times 1200 \mathrm{~mm}$. The mining of coal seams was simulated with a length of $500 \mathrm{~m}$ and a height of $240 \mathrm{~m}$. The unsimulated rock layer was compensated by an external load, and the pressure of overlying strata was simulated by uniform loading pressure. The thickness of the unsimulated rock layer is $230 \mathrm{~m}$, and the average volume weight of the rock layer is $2600 \mathrm{kN} / \mathrm{m}^{3}$. The added uniform loading pressure $q_{\mathrm{m}}$ is $1993 \mathrm{kPa}$. The two models used were the step-by-step mining model and the one-time mining model. The step-by-step mining model simulates the working face forward. The excavation step distance was set as $6 \mathrm{~m}$, and the total excavation length was $380 \mathrm{~m}$. During the excavation process, $60 \mathrm{~m}$ protective coal pillars were set up on both sides to eliminate the boundary effect. An inclined model was used to simulate the coal seam cutting process, using $310 \mathrm{~m}$ obtained from a one-time excavation simulation test.

Fine sand was used as skeletal material, calcium carbonate and gypsum were used as bonding materials, and mica powder was used to simulate the weak joint surface between rock layers. The model comprised 5 survey lines. The 5 th survey line was $20 \mathrm{~m}$ away from the coal seam, $40 \mathrm{~m}$ between the No. 3, No. 4, and No. 5 survey lines, and $60 \mathrm{~m}$ between the
No. 1, No. 2, and No. 3 survey lines. One displacement measuring point was placed every $20 \mathrm{~m}$ on each survey line, with a total of 24 displacement measuring points.

3.1.2. Analysis of Simulation Results. The overlying rock above the goaf gradually changes from an elastic state to a plastic state when the coal seam is mined. The overlying rock mass above the goaf moves and breaks when the working face advances to a certain distance, forming the caving zone, the fracture zone, and the bending subsidence zone. In the caving zone, the rock strata break into blocks and collapse. In the fracture zone, the fracture of the rock mass is fully developed; therefore, the survey line subsidence in the caving zone is relatively large, and the subsidence of different survey points on the same survey line fluctuates significantly. Although the fracture zone rocks have deformation and fractures, they have good continuity. The subsidence of the measuring point decreases with an increase in the measuring line position, and the subsidence law of each line in the fracture zone is similar. The "three zones" of mining overburden can be effectively categorized based on the above analysis.

The simulation results when working face mining to $380 \mathrm{~m}$ are shown in Figures 4(a)-4(c). When the mining area reaches $380 \mathrm{~m}$, the working face experiences 12 cycles of periodic pressure (Figure 4(a)). Statistical analysis showed that the first pressure distance was $50 \mathrm{~m}$, and the periodic pressure distance average was $25 \mathrm{~m}$. The change of the rock strata after each periodic pressure showed a certain regularity. The length of the rock layer collapsed after the periodic pressure was basically the same. All lengths were approximately equal to the periodic pressure step distance. However, the higher the overburden, the more backward the caving boundary was and the farther the projection of the caving boundary on the coal seam from the working face. The fragmented rocks appear irregular after the collapse of the caving zone, and a large difference in the degree of compaction was observed; therefore, it causes the same rock strata subsidence quantity disparity to be big. The sinking situation of each measuring line was drawn based on an analysis of the sinking value of each measuring point (Figure 4(b)). The final vertical displacement changes of the five survey lines of the overlying 


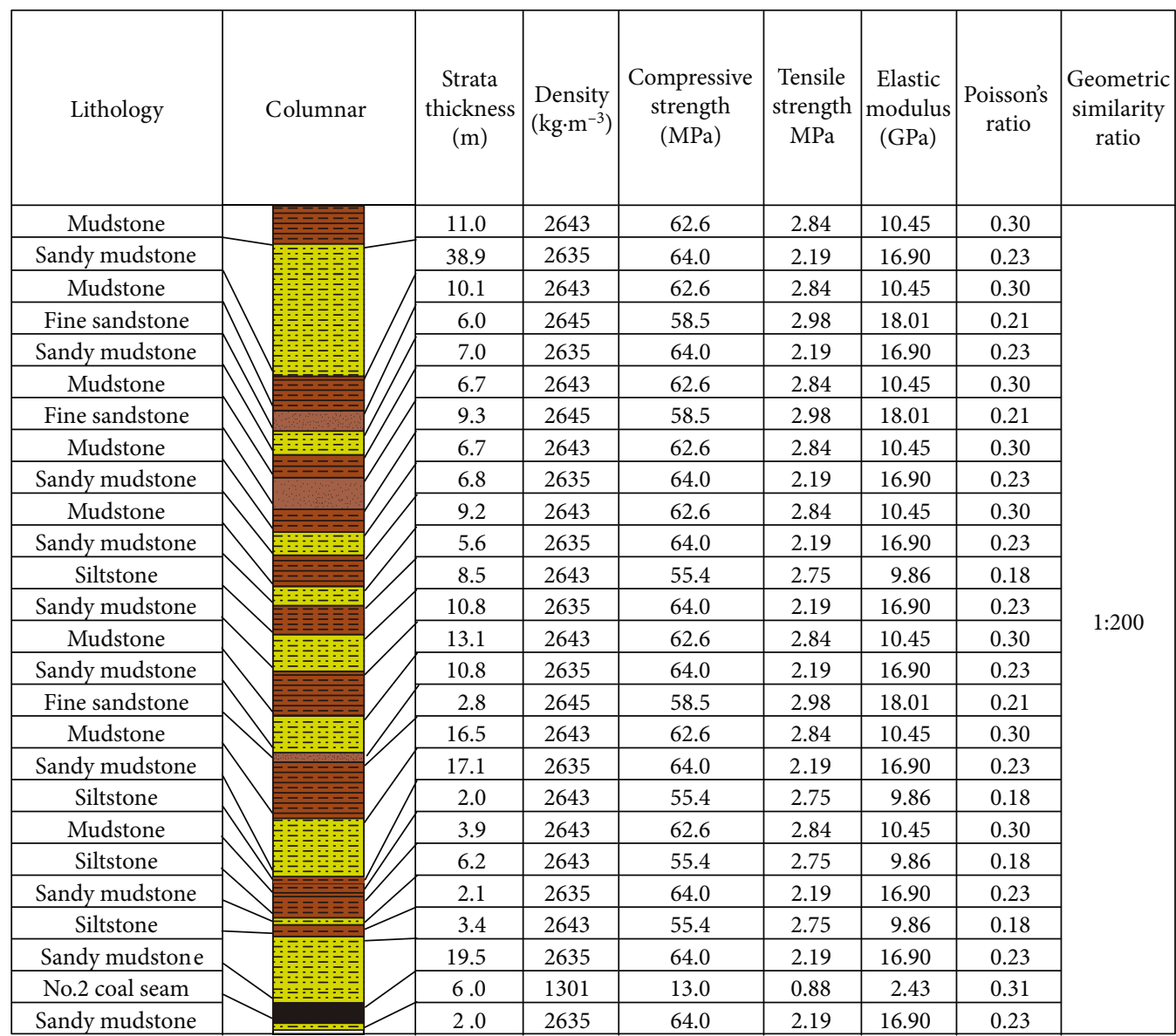

Figure 2: Mechanical parameters of overlying strata in the No. 2 coal seam.

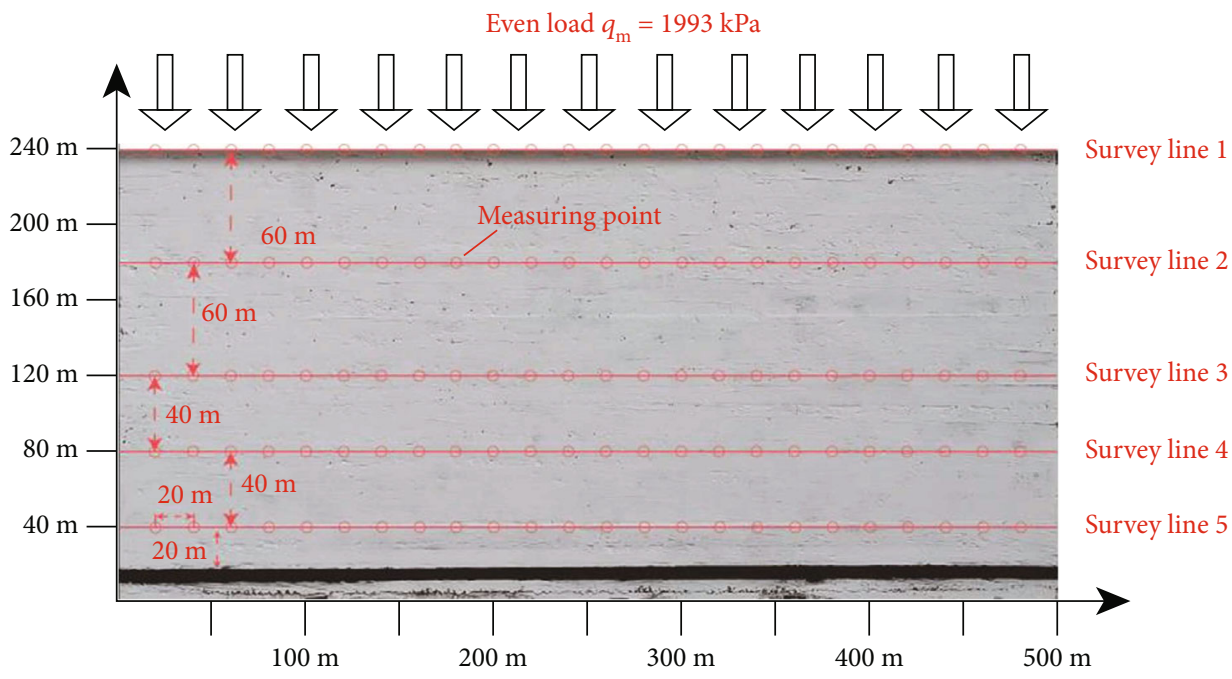

FIGURE 3: Physical similarity model of the working face.

strata after mining were visible. Survey line 5 showed the largest displacement and subsidence, which is close to the mining thickness of the coal seam, with a maximum value of $5.4 \mathrm{~m}$. The subsidence of survey line 4 and survey line 3 decreased sharply with a similar trend, with a maximum of $3.4 \mathrm{~m}$. The sinking amounts of survey line 1 and survey line
2 were the smallest, and the maximum sinking values were $2.3 \mathrm{~m}$ and $2.1 \mathrm{~m}$, respectively. These differences occur because survey line 5 is located in the caving zone of the coal roof of the goaf, survey lines 3 and 4 are located in the fracture zone of the coal roof of the goaf, and survey lines 1 and 2 are located above the fracture zone. The overlying 


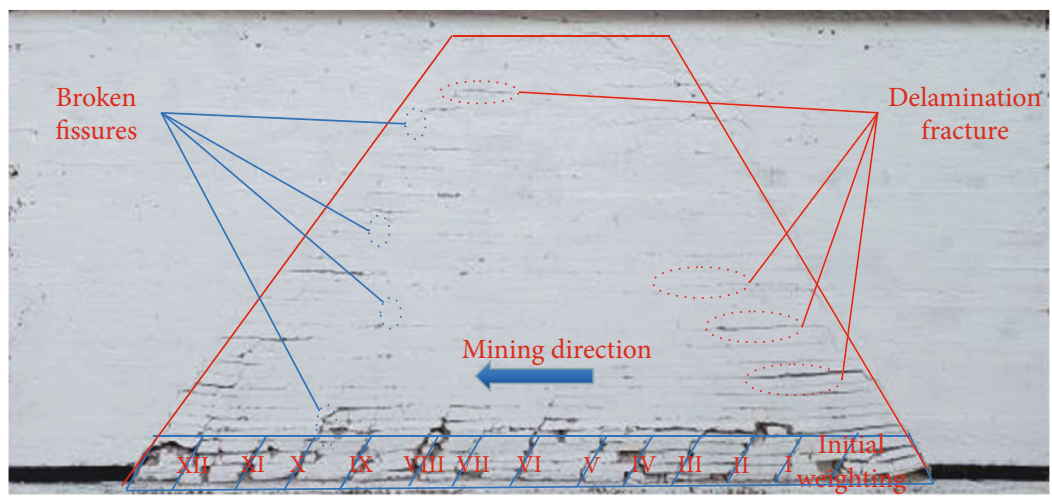

(a)
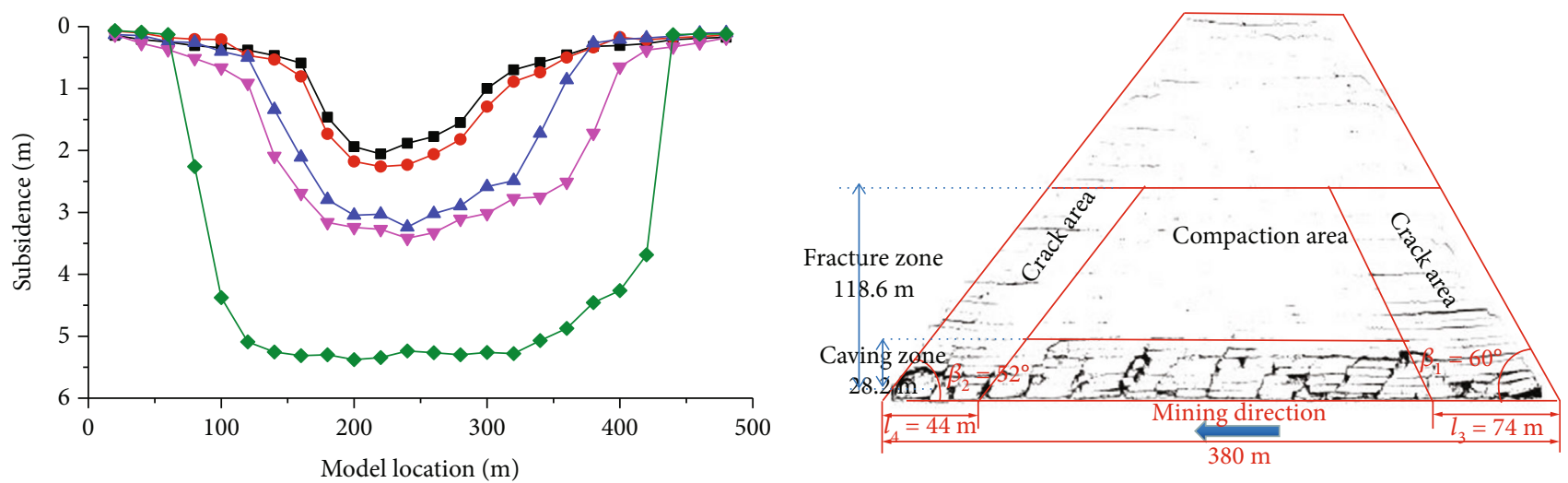

- Survey line 1

$\rightarrow$ Survey line 2

$\rightarrow$ Survey line 4

- Survey line 3

(b)

(c)

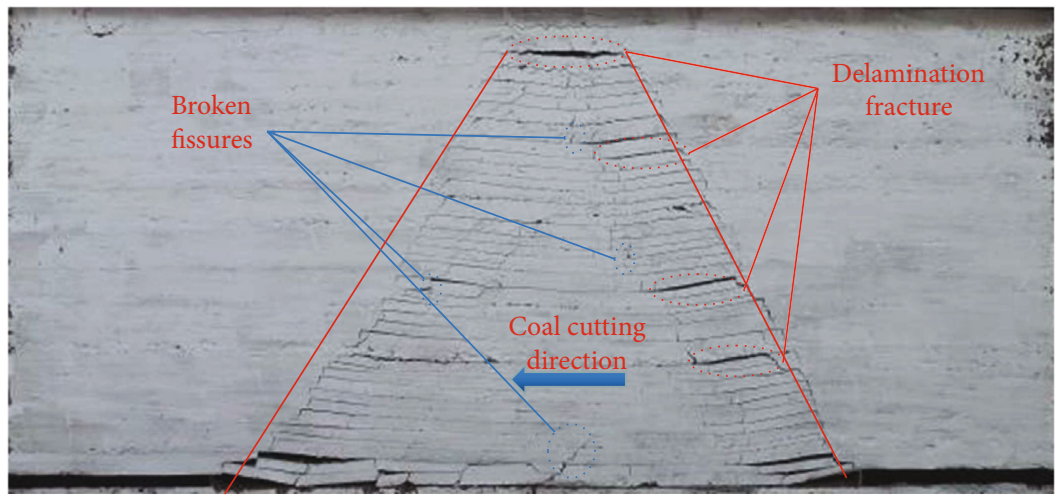

(d)

FIgure 4: Continued. 


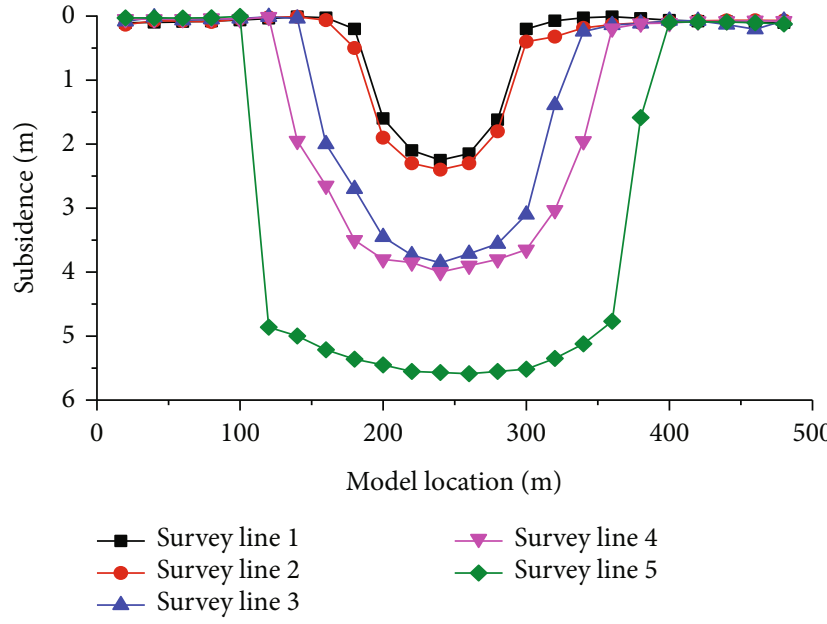

(e)

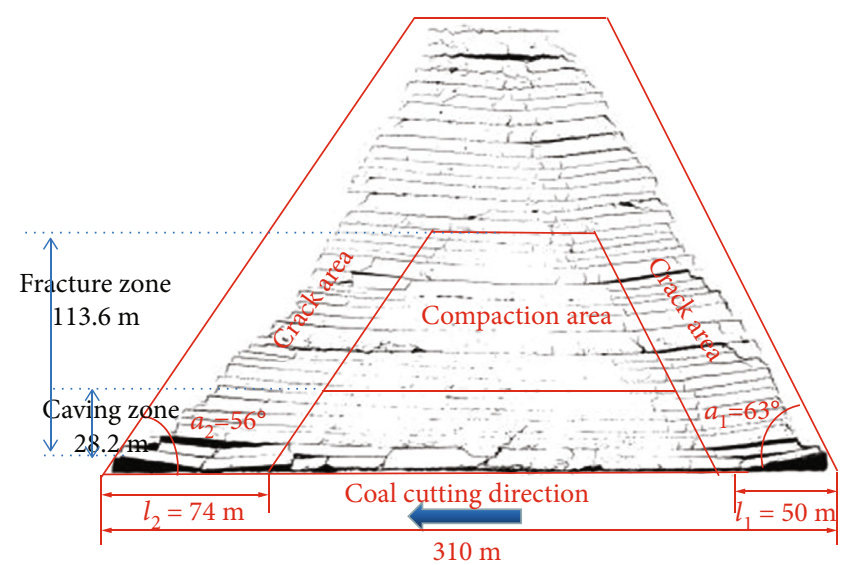

(f)

FIGURE 4: Migration and fracture development of overlying strata during coal seam mining.

strata fracture distribution network in the coal mining process is obtained through image processing of Figure 4(a). The distribution law of the caving zone and fissure zone is accurately shown in Figure 4(c). The maximum height of the caving zone of the strike model was $28.2 \mathrm{~m}$, the maximum height of the fracture zone was $118.6 \mathrm{~m}$, the caving angle at the cut eye was $60^{\circ}$, and the caving angle at the working face was $52^{\circ}$.

The simulation result of the one-time mining of the dip model is presented in Figures 4(d)-4(f). The rock formation collapsed after mining. One-time excavation is different from stepwise excavation in that coal cutting speed is faster, resulting in an increased distance of fracture of the rock. Analysis of the sinking value of the measurement points in Figure 4(e) shows that the sinking of the measurement points is generally similar to that of the strike model. The farther away from the roof of the coal seam, the smaller the sinking amount of the displacement measuring point. In addition, the displacement variation of each row of measuring points has a corresponding law. The sinking value of the displacement measuring point of survey line 5, which was $20 \mathrm{~m}$ away from the coal seam floor, was between $5.0 \mathrm{~m}$ and $5.6 \mathrm{~m}$. The maximum subsidence of survey line 4 from $60 \mathrm{~m}$ of the coal seam floor was $4.0 \mathrm{~m}$, and the maximum subsidence of survey line 3 was $3.8 \mathrm{~m}$. These findings show that the farther the distance from the coal roof is, the smaller the subsidence of the survey point. Analysis of the fracture distribution network shows that the cracks in the middle of the goaf are compacted, whereas the cracks on both sides are relatively developed (Figure 4(f)). Several broken fracture gaps occur below $28.2 \mathrm{~m}$ from the roof of the coal seam, which are relatively messy, and belong to the caving zone. Fractures from the upper part of the caving zone to a height of $113.6 \mathrm{~m}$ are relatively developed and belong to the fracture zone. Measurement of the caving angle of coal seams was inclined to one-off mining. The caving angle of the coal cutter tail was $56^{\circ}$, whereas the caving angle of the coal cutter head was $63^{\circ}$.

3.2. Field Test of Fracture Evolution of Overlying Strata. The field test is the most intuitive and reliable method to study the development of "three-zone" cracks in overlying strata $[32,33]$. Two drill holes are arranged in the coal wall of the return airway of the working face. The location and development of fissures in the borehole under the effect of mining were monitored using the drilling peep method. Borehole layout parameters are shown in Table 1, and the layout is shown in Figure 5.

By observing the development inside the borehole, the fracture area of goaf is analyzed during the process of mining (Figure 6). Analysis of the No. I hole at a depth of $24 \mathrm{~m}$ showed that the hole wall was complete, and only small cracks were produced, with no large penetrating cracks. A large number of cracks occurred in the area from $24 \mathrm{~m}$ to $59 \mathrm{~m}$, resulting in the collapse of the hole wall. The cracks were developed and irregular. In addition, observation was done from drilling at $59 \mathrm{~m}$ to the bottom of the hole. The fissures were stable in this area, and regular penetrating fissures and separation fissures were observed. Analysis of the No. II hole showed that the hole wall was intact within $26 \mathrm{~m}$ deep before drilling, and a large amount of broken rock appeared in the area from $26 \mathrm{~m}$ to $93 \mathrm{~m}$. Further observation showed that the borehole was significantly deformed. Moreover, it was gradually blocked before the entrance of the bottom of the borehole, indicating that the borehole had reached the goaf compaction zone.

Borehole No. I did not enter the caving area behind the working face before $24 \mathrm{~m}$; therefore, the borehole wall in this area was complete. After entry to the goaf, it first went through the caving zone, resulting in shredding and shedding of rocks in the borehole. The borehole entered the fracture zone at a depth of $59 \mathrm{~m}$. The fracture development was regular, and the rock integrity was good. The front section of borehole No. II was similar to that of borehole No. I. Several rock blocks accumulated in the borehole at a depth of $26 \mathrm{~m}$ into the caving zone of goaf, whereas at $93 \mathrm{~m}$ deep, the borehole entered the goaf compaction area and was gradually blocked.

The location of the hole was determined by drawing the vertical view and front view of borehole No. I and No. II. 
TABLE 1: Drilling parameters.

\begin{tabular}{lccccc}
\hline $\begin{array}{l}\text { Drilling } \\
\text { number }\end{array}$ & Hole position & $\begin{array}{c}\text { Drilling diameter } \\
(\mathrm{mm})\end{array}$ & $\begin{array}{c}\text { Drilling depth } \\
(\mathrm{m})\end{array}$ & $\begin{array}{c}\text { Inclination } \\
\left({ }^{\circ}\right)\end{array}$ & $\begin{array}{c}\text { Included angle with laneway } \\
\text { midline }\left({ }^{\circ}\right)\end{array}$ \\
\hline $1 \#$ & The coal wall at 20m away from the & & 120 & +27.0 & 12.0 \\
$2 \#$ & working face & $\phi 73$ & 135 & +12.0 & 35.0 \\
\hline
\end{tabular}

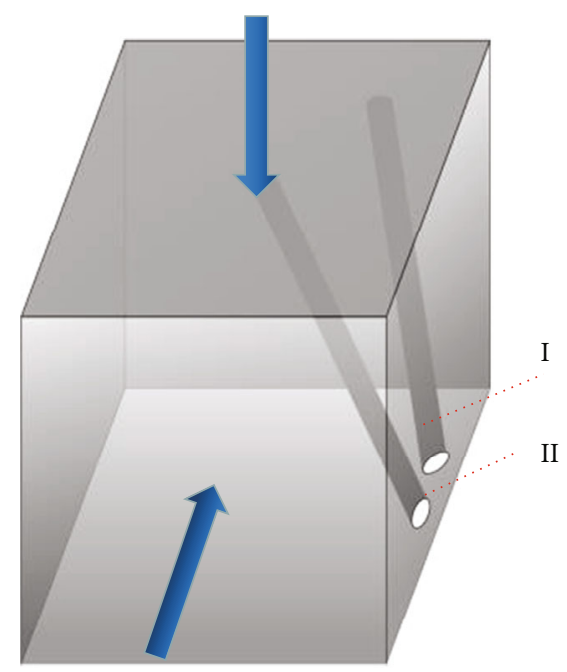

FIgURE 5: Schematic of the peephole.

Analysis of the measured results was done through borehole peeking. Borehole No. I entered the goaf zone and fracture zone but did not enter the compaction zone. Borehole No. II entered the caving zone and compaction zone but did not enter the fracture zone. The height of the caving zone was between $26 \mathrm{~m}$ and $28 \mathrm{~m}$, and the compaction area was about $50 \mathrm{~m}$ from the mining face and $22 \mathrm{~m} \sim 52 \mathrm{~m}$ from the return air roadway.

\section{Law of Gas Migration in Goaf under the Influence of Mining}

\subsection{Law of Gas Emission from the Fracture Zone}

\subsubsection{Dynamic Gas Emission Model of the Working Face}

(1) Coal Wall Gas Emission Model. The fresh coal wall was constantly exposed during the mining process of the working face, and a constant gas pressure gradient was observed in front of the working face. Therefore, the gas in the coal seam flowed to the working face. The intensity of gas emission decreased with an increase in coal wall exposure time. The amount of coal wall gas emission mainly depends on the original coal seam gas pressure, coal seam permeability, and coal gas adsorption performance. Under constant mining conditions, the gas emission intensity has the following function relationship with the exposure time:

$$
V_{1}=V_{\mathrm{r}}(1+t)^{-n_{1}}
$$

where $V_{1}$ represents the gas emission intensity per unit area of the coal wall at time $t, \mathrm{~m}^{3} /\left(\mathrm{m}^{2} \cdot \mathrm{min}\right) ; V_{\mathrm{r}}$ represents the gas emission intensity per unit area of the coal wall at the initial moment, $\mathrm{m}^{3} /\left(\mathrm{m}^{2} \cdot \mathrm{min}\right) ; t$ represents the coal wall exposure time, min; and $n_{1}$ represents the coal wall gas emission attenuation coefficient, $\mathrm{min}^{-1}$.

The cumulative gas emission per unit area of the coal wall during normal advancement of the working face is

$$
q_{1}=\int_{0}^{t} V_{1} d t
$$

Absolute gas emission from the coal wall of the working face is calculated as follows:

$$
Q_{1}=S \bullet q_{1}
$$

The effective exposed area of the coal wall of the working face is divided into the front coal wall $S_{1}$ and the top coal wall $S_{2}$. Gas emission from the coal wall is the sum of the two parts:

$$
\begin{aligned}
& S=S_{1}+S_{2}, \\
& S_{1}=l \bullet h_{0}, \\
& S_{2}=l \bullet w .
\end{aligned}
$$

In the formula, $S$ represents the effective exposed area of the coal wall of the working face, $\mathrm{m}^{2} ; l$ represents the length of the working face, $\mathrm{m} ; h_{0}$ represents the height of the working face, $\mathrm{m}$; and $w$ represents the width of the working surface, $\mathrm{m}$.

The absolute gas emission from the coal wall is calculated through organization and integration of formulas (1)-(6) as follows:

$$
Q_{1}=V_{\mathrm{r}}\left(\frac{(1+t)^{1-n_{1}}}{1-n_{1}}-\frac{1}{1-n_{1}}\right) l\left(h_{0}+w\right)
$$

(2) The Law of Coal Gas Emission from Coal Mining. Part of the gas in the working face is released during the mining process as the coal body is broken into different particle sizes. The amount of emission is mainly related to factors such as coal amount, desorption gas content, desorption strength, and exposure time. In the process of mining, the gas desorption strength of coal is correlated with the exposure time of coal. The mathematical expression of this relationship is

$$
V_{2}=V_{c} \bullet e^{-n_{2} t}
$$




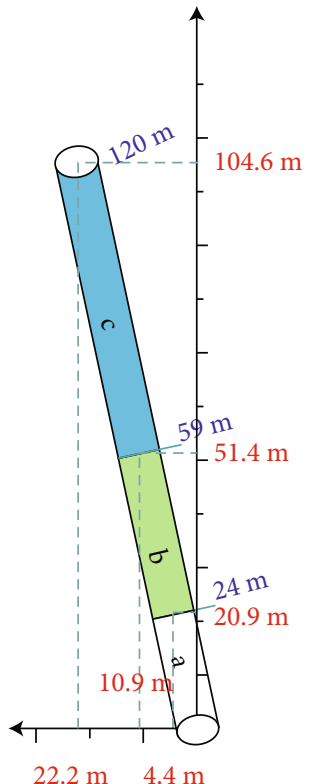

$22.2 \mathrm{~m} \quad 4.4 \mathrm{~m}$

Vertical view

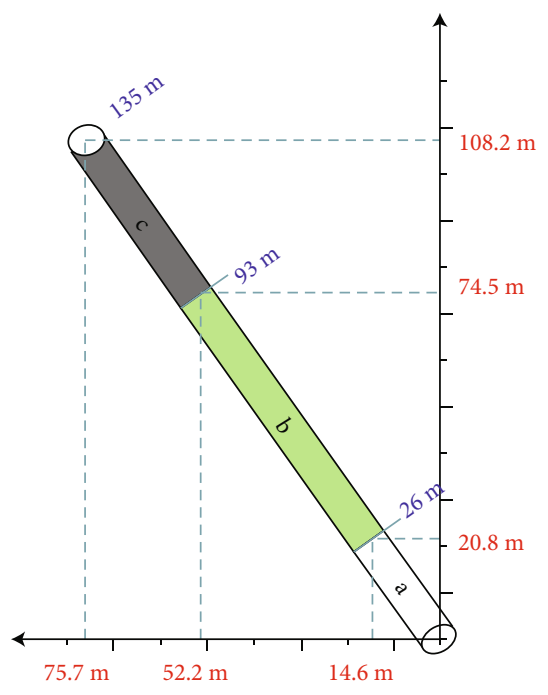

Vertical view
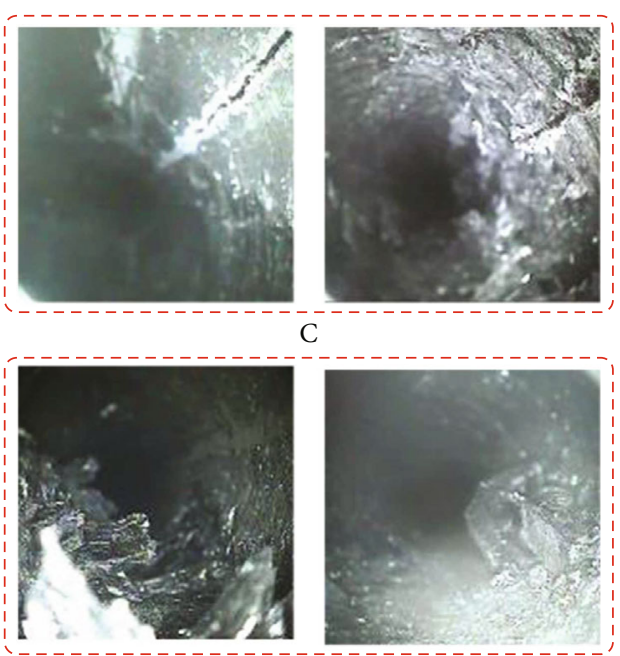

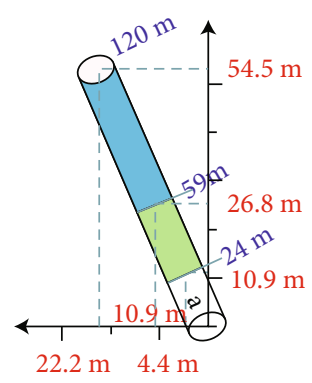

Main view

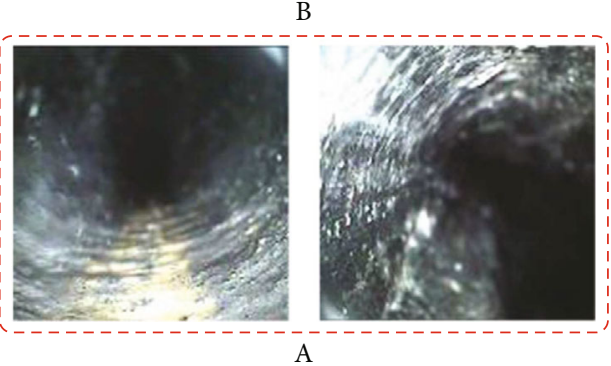

Drilling peep view

(a) Borehole No. I

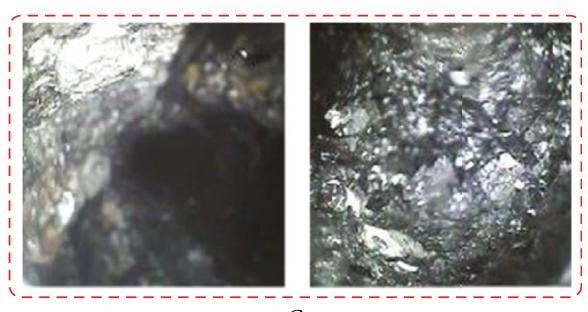

C

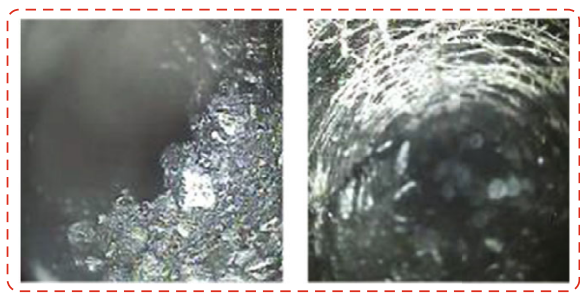

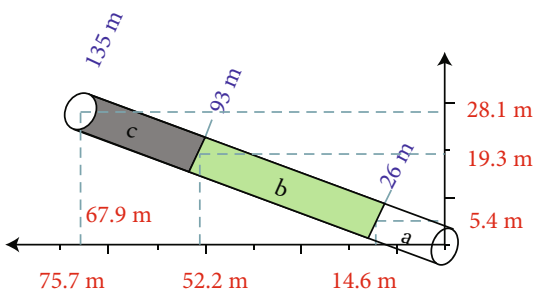

Main view

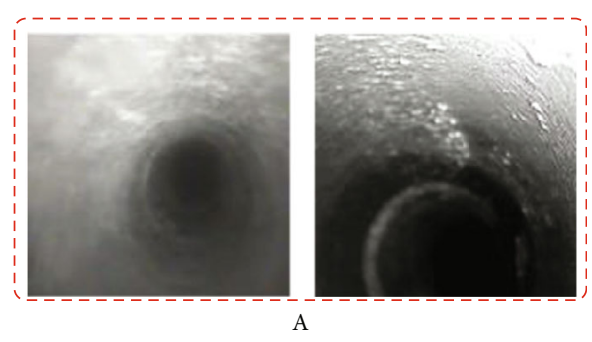

Drilling peep view

(b) Borehole No. II

FIgURE 6: Observation results of drill holes during mining. 
whereby $V_{2}$ represents the gas emission intensity at time $t$ when the mined coal stays at the working face, $\mathrm{m}^{3} /(\mathrm{t} \cdot \mathrm{min})$; $n_{2}$ represents the attenuation coefficient of gas emission from coal mining, $\min ^{-1} ; V_{\mathrm{c}}$ represents the initial gas emission intensity of broken coal, $\mathrm{m}^{3} /(\mathrm{t} \cdot \mathrm{min})$; and $t$ represents the residence time of mined coal on the working face, min.

During the production period, the coal mine gas emission $Q_{2}$ is affected by the mined coal quality and gas desorption strength. The mathematical expression of this relationship is as shown below:

$$
Q_{2}=\int_{0}^{t} d V_{2} \cdot M_{2} \frac{W_{0}}{1.5}
$$

In the formula, $d V_{2}$ represents the total gas emission intensity of coal mined at time $d t, \mathrm{~m}^{3} /(\mathrm{t} \cdot \mathrm{min}) ; M_{2}$ represents the coal mining quality, $\mathrm{t}$; $t$ represents the time of coal transportation, that is, the time when the coal mass is transported out of the working face through the scraper conveyor and the belt, min; and $W_{0}$ represents the desorption gas content amount of the coal mass, $\mathrm{m}^{3} / \mathrm{t}$.

$M_{2}$ is calculated as follows:

$$
M_{2}=R h_{1} \rho d v_{0}
$$

whereby $h_{1}$ represents the coal seam thickness, $\mathrm{m} ; \rho$ is the coal density, $\mathrm{t} / \mathrm{m}^{3} ; d$ is the shearer cutting depth, $\mathrm{m} ; R$ represents the rate of recovery, $\%$; and $v_{0}$ represents the coal cutting speed, $\mathrm{m} / \mathrm{min}$.

The amount of gas emission in the coal mining process of the working face can be obtained by combining equations (8)-(10) and integrating $t$ as follows:

$$
Q_{2}=\frac{2}{3} R h_{1} \rho d v_{0} W_{0}\left[\frac{V_{\mathrm{c}}}{n_{2}}\left(1-e^{-n_{2} t}\right)\right] .
$$

(3) Model of Gas Emission from Remnant Coal in Goaf. In the process of comprehensive mining, a relationship between the desorption strength of the remnant coal gas and the exposure time of the coal mass is observed. The relationship is similar to the change law of the gas emission intensity of the mined coal. The mathematical expression of this relationship is

$$
V_{3}=V_{c} \bullet e^{-n_{3} t} \text {. }
$$

In the formula, $V_{3}$ represents the gas emission intensity at time $t$ of unit remnant coal in the goaf, $\mathrm{m}^{3} /(\mathrm{t} \cdot \mathrm{min}) ; n_{3}$ represents the gas emission attenuation coefficient of remnant coal, $\min ^{-1}$; and $t$ represents the stay time of remnant coal in goaf, min.

Gas emission from the goaf is mainly affected by the recovery rate during the process of comprehensive mining. A high recovery rate leads to less remnant coal; therefore, the gas emission in the goaf is lower. The effective gas emission in goaf is calculated as follows:

$$
Q_{3}=\int_{0}^{t} d V_{3} \cdot M_{3} \frac{W_{0}}{1.5}
$$

In the formula, $Q_{3}$ represents the gas emission from goaf, $\mathrm{m}^{3} ; d V_{3}$ represents the gas emission intensity of remnant coal in goaf at time $d t, \mathrm{~m}^{3} /(\mathrm{t} \cdot \mathrm{min}) ; M_{3}$ represents the quality of remnant coal in goaf at time $t, \mathrm{t} ; W_{0}$ represents the desorption gas content amount of the coal mass, $\mathrm{m}^{3} / \mathrm{t}$; and $t$ represents the exposure time of remnant coal in goaf, min.

The quality of the remnant coal in goaf depends on the recovery rate of the working face and is calculated as follows:

$$
M_{3}=(1-R) l h_{1} \rho l_{0}
$$

In the formula, $h_{1}$ represents the coal seam thickness, $\mathrm{m}$; $\rho$ represents the coal density, $\mathrm{t} / \mathrm{m}^{3} ; R$ represents the rate of recovery, \%; $l$ represents the length of the working face, $\mathrm{m}$; and $l_{0}$ represents the depth of goaf, $\mathrm{m}$.

The amount of gas emission from the remnant coal in goaf can be obtained by combining formulas (12)-(14) and integrating

$$
Q_{3}=\frac{2 V_{c}}{3 n_{3}}\left(1-e^{-n_{3} t}\right)(1-R) l h_{1} \rho l_{0} W_{0}
$$

\subsubsection{Gas Migration Model of the Mining Fracture Area}

(1) Gas Migration Model in the Working Face. The NavierStokes equation accurately describes the flow of fluid in the pipeline. The airflow in the coal mine roadway and mining face can be simplified to pipeline flow [34]. In this study, the Navier-Stokes equation was used as the governing equation of airflow in the working face, and the dependent variables were the velocity vector $\left(u_{\mathrm{ns}}\right)$ and pressure $\left(p_{\mathrm{ns}}\right)$. The equation is expressed as follows:

$$
\begin{gathered}
-\nabla \bullet \eta\left(\nabla u_{\mathrm{ns}}+\left(\nabla u_{\mathrm{ns}}\right)^{\mathrm{T}}\right)+\rho u_{\mathrm{ns}} \bullet \nabla u_{\mathrm{ns}}+\nabla p_{\mathrm{ns}}=0, \\
\nabla \bullet u_{\mathrm{ns}}=0,
\end{gathered}
$$

whereby $\eta$ represents the viscosity coefficient, $\mathrm{kg} /(\mathrm{m} \cdot \mathrm{s})$; and $\rho$ is the fluid density, $\mathrm{kg} / \mathrm{m}^{3}$.

(2) Gas Migration Model in Goaf. The goaf is affected by the collapse of the roof and is filled with coal, and there are a lot of cracks and cavities around the coal. The state of the gas flow in goaf is between the Darcy seepage and the NavierStokes pipeline flow. This state can be described by the Brinkman equations, that is, the fluid flow equation in the porous medium. The equation is mainly affected by the velocity vector $\left(u_{\mathrm{br}}\right)$, the pressure $\left(p_{\mathrm{br}}\right)$, and the permeability and porosity of the porous medium. Moreover, the permeability and porosity in goaf are correlated with the coefficient of dilatation of rock collapse. This relationship can be expressed as shown below [35]: 


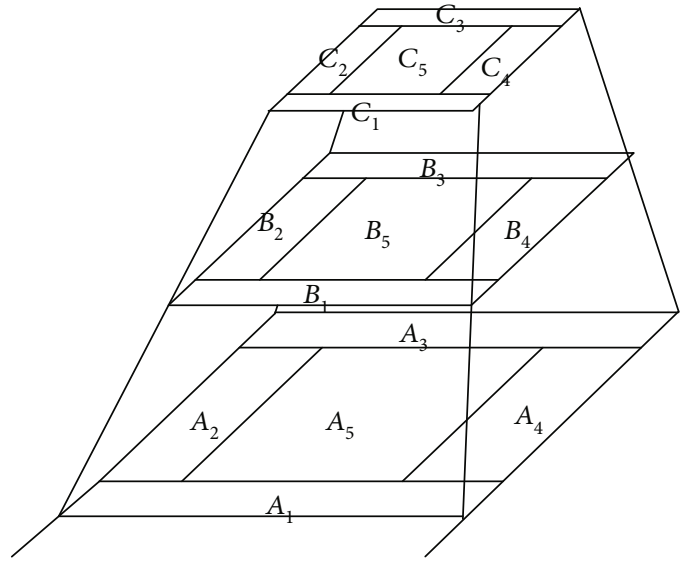

(a) Division of the mining fissure field

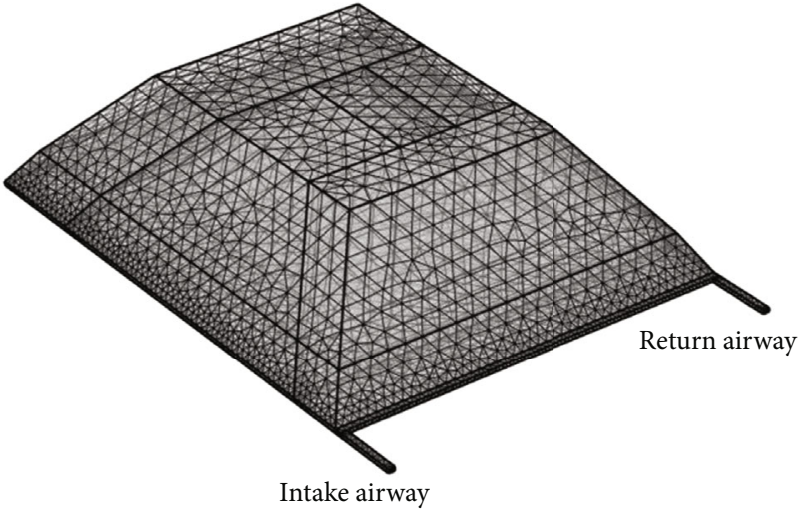

(b) Numerical model grid segmentation

Figure 7: Numerical model of gas migration in goaf.

TABle 2: Coefficient of dilatation of rock collapse of each area.

\begin{tabular}{lcccccccc}
\hline Area & $A_{1}, B_{1}$ & $A_{2}, B_{2}$ & $A_{5}, B_{5}$ & $A_{4}, B_{4}$ & $A_{3}, B_{3}$ & $C_{1}, C_{3}$ & $C_{5}$ & $C_{2}, C_{4}$ \\
\hline Dilatation coefficient $k_{\mathrm{p}}$ & 1.2 & 1.14 & 1.05 & 1.12 & 1.07 & 1.05 & 1.07 \\
Porosity & 0.17 & 0.12 & 0.05 & 0.11 & 0.07 & 0.05 & 0.07 & 0.06 \\
Permeability $\left(10^{-6} / \mathrm{m}^{2}\right)$ & 1.45 & 1.2 & 0.03 & 1.2 & 0.14 & 0.14 & 0.007 & 0.3 \\
\hline
\end{tabular}

$$
\frac{\rho}{\varepsilon}\left(\frac{\partial u_{\mathrm{br}}}{\partial t}\right)+\left(\frac{\mu}{k}\right) u_{\mathrm{br}}=-\nabla p_{\mathrm{br}}+\nabla\left(\frac{\mu}{\varepsilon}\left(u_{\mathrm{br}}+\left(\nabla u_{\mathrm{br}}\right)^{\mathrm{T}}\right)\right)+F
$$

$$
\begin{aligned}
\nabla \bullet u_{\mathrm{br}} & =0, \\
k & =\frac{\varepsilon^{3} d_{\mathrm{m}}^{2}}{150(1-\varepsilon)^{2}}, \\
\varepsilon & =1-\frac{1}{k_{\mathrm{p}}},
\end{aligned}
$$

whereby $\eta$ represents the viscosity coefficient, $\mathrm{kg} /(\mathrm{m} \cdot \mathrm{s}) ; \rho$ is the fluid density, $\mathrm{kg} / \mathrm{m}^{3} ; \varepsilon$ is the porosity; $k$ is the permeability coefficient; $k_{\mathrm{p}}$ is the coefficient of dilatation of rock collapse; and $d_{\mathrm{m}}$ is the average particle diameter of the porous medium, $\mathrm{m}$.

The fluid flow equations in the porous medium relative to the velocity vector $\left(u_{\mathrm{br}}\right)$, pressure $\left(p_{\mathrm{br}}\right)$, and coefficient of dilatation of rock collapse $\left(k_{\mathrm{p}}\right)$ can be obtained by reorganizing equations (18)-(21) as follows:

$\frac{\rho}{\varepsilon}\left(\frac{\partial u_{\mathrm{br}}}{\partial t}\right)+\left(\frac{150 \mu k_{\mathrm{p}}}{\left(k_{\mathrm{p}}-1\right)^{3} d_{\mathrm{m}}^{2}}\right) u_{\mathrm{br}}=-\nabla p_{\mathrm{br}}+\nabla\left(\frac{\mu k_{\mathrm{p}}}{k_{\mathrm{p}}-1}\left(u_{\mathrm{br}}+\left(\nabla u_{\mathrm{br}}\right)^{\mathrm{T}}\right)\right)+F$.

\subsection{Numerical Simulation of Gas Migration in Goaf}

4.2.1. Numerical Model Establishment. The working face and mining fissure field can be simplified based on the above- mentioned physical test and the theoretical model of gas migration. The model is divided into 15 regions based on the different coefficients of dilatation of rock collapse of the overburden rock caused by mining (Figure 7(a)).

Based on the physical similarity simulation, a gas migration model in goaf was established by COMSOL numerical simulation, as shown in Figure 7(b).

The length and width of the goaf in the model are $400 \mathrm{~m}$ and $310 \mathrm{~m}$, respectively. In the model, the heights of the goaf, caving zone, and fracture zone are $3 \mathrm{~m}, 28.2 \mathrm{~m}$, and $90.4 \mathrm{~m}$, respectively. And the caving angle in the inner part of the goaf after the coal seam was mined was $60^{\circ}$, the caving angle in the location of the coal face was $52^{\circ}$, the caving angle on the side of the return airflow roadway was $63^{\circ}$, and the caving angle on the side of the intake airflow roadway was $56^{\circ}$.

The height of the working face was $3 \mathrm{~m}$, the width was $5 \mathrm{~m}$, and the length was $310 \mathrm{~m}$ based on the actual mine conditions. The wind speed was $2.26 \mathrm{~m} / \mathrm{s}$, the air density was $1.29 \mathrm{~kg} / \mathrm{m}^{3}$, the gas density was $0.714 \mathrm{~kg} / \mathrm{m}^{3}$, the air dynamic viscosity coefficient was $5 \times 10^{-5} \mathrm{~Pa} \cdot \mathrm{s}$, and the gas pressure was $0.2 \mathrm{MPa}$. The outer boundary condition of the simulation model is air-impermeable, which indicates that the gas cannot travel through the boundary. The areas that contain the caving zone and fracture zone are in free seepage conditions. Also, the roadway and working face are both set in the freeflow model of gas.

The gas migration in goaf was affected by permeability and porosity, as shown by the abovementioned gas migration model in goaf. In addition, the porosity and permeability are correlated with the coefficient of dilatation of rock collapse. Therefore, the coefficient of dilatation of rock collapse is calculated based on the actual situation in the field. $A_{n}$ 


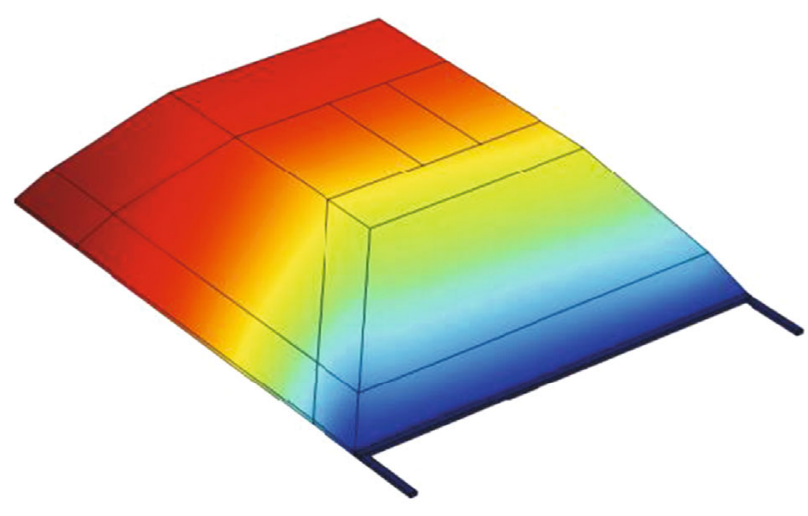

(a) Figure of gas distribution

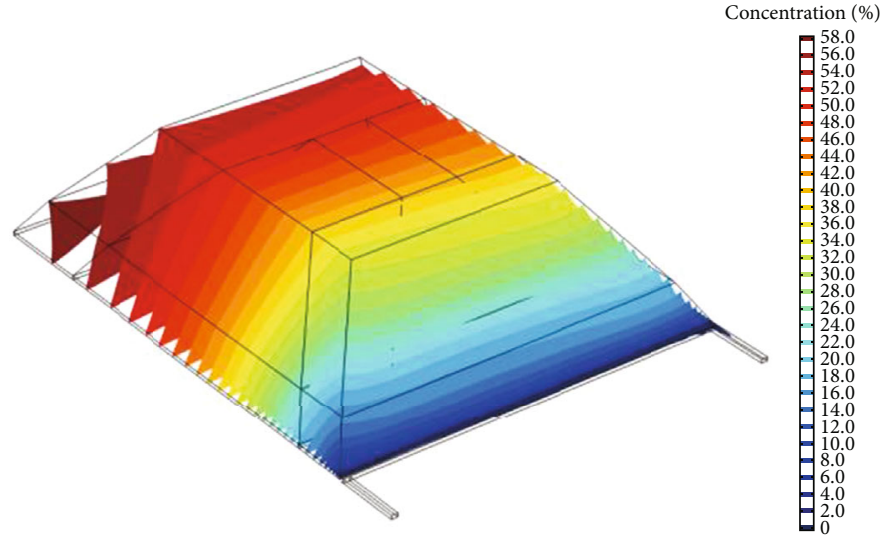

(b) Figure of concentration isosurface map

FIgURE 8: Three-dimensional distribution of gas concentration in goaf.

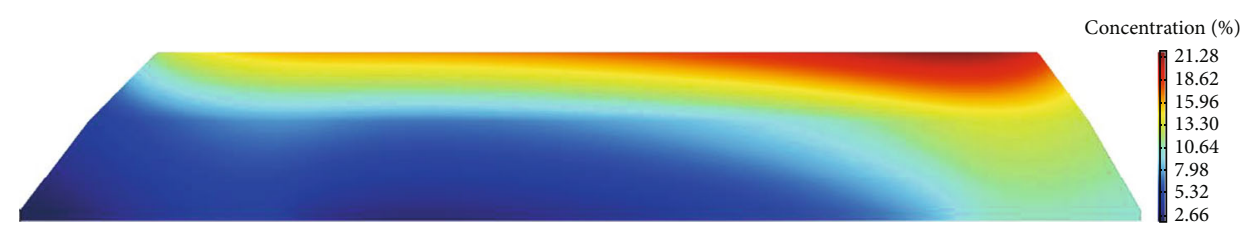

Figure 9: Plane diagram of gas concentration distribution at a depth of $45 \mathrm{~m}$ in goaf.

represents the goaf, $B_{n}$ represents the caving zone, and $C_{n}$ represents the fissure zone. Specific values are shown in Table 2 .

4.2.2. Analysis of Numerical Simulation Results. Under the influence of coal seam mining, gas migration is affected by gas concentration and pressure. The development of fissures of the overlying strata in various areas is very different. Therefore, the distribution of gas in different areas of the goaf is also different. During the diffusion of gas in the overburden fissure area, the distribution of the mining fissure field plays a vital role in gas migration. The gas concentration results based on the distribution law of the mining fissure field are shown in Figure 8.

The distribution patterns of gas with different concentrations are shown in Figure 8. The gas concentration increases gradually in the deep area of goaf along the coal seam strike. The gas isosurface was dense, and the gradient of gas concentration was relatively large near the return airway corner of the working face. The gas migrates to the return airway corner direction due to the influence of air leakage near the working face, which makes the gas concentration increase gradually from the inlet wind corner to the return airway corner, in the direction of the coal seam inclination of the working face. The gas reaches the maximum value at the return airway corner. The distribution of gas concentration in the vertical direction shows that the gas concentration in the fracture zone at the return airway corner is significantly higher compared with that in the caving zone.

The plane gas distribution at $45 \mathrm{~m}$ inside the extracted working face is shown in Figure 9. On the plane at a depth

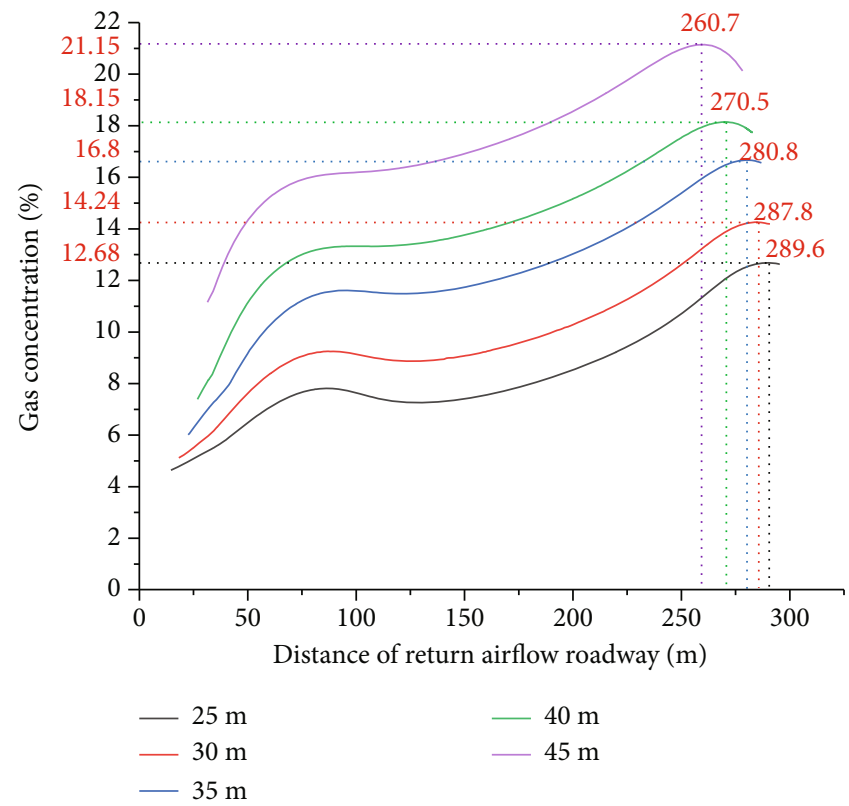

FIGURE 10: Gas concentration against different heights at a depth of $45 \mathrm{~m}$ in goaf.

of $45 \mathrm{~m}$ in goaf, the gas presents a "saddle-shaped" distribution as a whole. The highest concentration is distributed in the area of the upper caving zone and lower part of the fracture zone. The gas concentration data is extracted from the tangent line at the height of $25 \mathrm{~m}, 30 \mathrm{~m}, 35 \mathrm{~m}, 40 \mathrm{~m}$, and $45 \mathrm{~m}$ at a depth of $45 \mathrm{~m}$ in goaf for quantitative analysis. A curve of gas concentration variation along coal seam 
TABle 3: Parameters of the high-level directional long borehole.

\begin{tabular}{|c|c|c|c|c|c|c|}
\hline $\begin{array}{l}\text { Drilling } \\
\text { site }\end{array}$ & $\begin{array}{l}\text { Drilling } \\
\text { number }\end{array}$ & $\begin{array}{l}\text { Design layer } \\
(\mathrm{m})\end{array}$ & $\begin{array}{l}\text { Design horizontal distance } \\
\qquad(\mathrm{m})\end{array}$ & $\begin{array}{l}\text { Construction layer } \\
(\mathrm{m})\end{array}$ & $\begin{array}{l}\text { Construction horizontal } \\
\text { distance }(\mathrm{m})\end{array}$ & $\begin{array}{l}\text { Length } \\
(\mathrm{m})\end{array}$ \\
\hline \multirow{4}{*}{ 6\# } & $6-1$ & 45 & 50 & 43 & 50 & 483 \\
\hline & $6-2$ & 40 & 40 & 41 & 40 & 480 \\
\hline & $6-3$ & 35 & 30 & 33 & 29 & 477 \\
\hline & $6-4$ & 25 & 20 & 24 & 19 & 474 \\
\hline
\end{tabular}

tendency was constructed, as shown in Figure 10. The curve shows that from the intake airflow roadway of the working face to the return airflow roadway, the gas concentration gradually increases, then decreases and increases again. Thereafter, it gradually decreases when it reaches the highest point. The maximum gas concentration of the tangent at different heights is different. When the heights are $25 \mathrm{~m}, 30 \mathrm{~m}$, $35 \mathrm{~m}, 40 \mathrm{~m}$, and $45 \mathrm{~m}$, the distances from the highest point of gas concentration to the return airflow roadway are $20.4 \mathrm{~m}, 22.2 \mathrm{~m}, 29.2 \mathrm{~m}, 39.5 \mathrm{~m}$, and $49.3 \mathrm{~m}$, respectively. The highest gas concentration at each height was $12.68 \%$, $14.24 \%, 16.8 \%, 18.15 \%$, and $21.15 \%$, respectively, and the gas concentration showed an increasing trend in the vertical direction.

The effective extraction distance of drill holes in the overlying rock fissure of the goaf is affected by the overlying rock collapse. The results from physical simulation show that the drill holes should be located in the gas enrichment zone of the crack area of the overburden rock caused by mining. Moreover, the drill holes should mainly extract gas at a depth of $40 \mathrm{~m}-50 \mathrm{~m}$ from the working face, thereby changing the upper corner gas flow field and ensuring safety production at the working face.

Based on this, the on-site setting of the high directional long borehole is a balanced trade-off with the extraction capacity and economic benefits. The high directional long borehole is set as follows. The high directional long borehole is set within $50 \mathrm{~m}$ from the return airflow roadway of the working face. The bottom location of the high directional long borehole is arranged at the position of $20 \mathrm{~m}, 30 \mathrm{~m}$, $40 \mathrm{~m}$, and $50 \mathrm{~m}$ from the horizontal distance of the return airflow roadway, and the design layers of the high directional long borehole are $20-30 \mathrm{~m}, 30-40 \mathrm{~m}, 40-50 \mathrm{~m}$, and $40-50 \mathrm{~m}$, respectively.

\section{Practical Application}

In the normal mining process of the test working face, affected by gas migration in goaf, the gas concentration of the return airway corner of the working face is relatively high, which affects safety production. Unsafe gas emission cannot be effectively solved by ventilation. Reasonable high directional long borehole layout parameters are designed to extract gas in the goaf overburden fracture area based on the analysis of the law of fracture distribution of overlying strata and gas migration in goaf, thus reducing the gas emission in goaf and changing the gas flow field near the return airway corner. The location of the gas enrichment area of the gas migration process can be effectively determined by tracking the gas concentration of the working face and the return airway corner during the mining process and realtime monitoring of the gas concentration and the gas extraction volume of the high-position long borehole.

5.1. Drilling Location Selection. The primary task of gas extraction in the fracture zone of the goaf is designing the extraction method and parameters based on the determination of the range of the high-concentration gas enrichment area. Regional determination of the gas enrichment area is important for efficient extraction. Choosing the location of the directional long boreholes in the gas enrichment area can help in effectively extracting high-concentration gas and achieving safety production in the mine. A reasonable high-level directional long borehole parameter is designed to carry out pressure relief gas extraction in the fissure zone of goaf based on these findings. The design parameters are shown in Table 3, and a high-level directional long borehole arrangement is shown in Figure 11.

\subsection{Effect Investigation}

5.2.1. Extraction Effect. The extraction effect was determined through the real-time monitoring of the gas extraction effect of the high-level directional long borehole during the mining of the working face (Figure 12). The findings show that in the normal mining process of the working face, the four highlevel directional long boreholes in the drilling site extraction effects were improved. The extraction concentrations of the four boreholes were $11.0 \%-26.2 \%, 7.5 \%-32.6 \%, 10.0 \%$ $20.0 \%$, and $7.3 \%-19.0 \%$. The average extraction concentrations were $19.6 \%, 17.5 \%, 15.2 \%$, and $13.0 \%$. The minimum gas extraction purity of the four boreholes was more than $0.4 \mathrm{~m}^{3} / \mathrm{min}$, and the maximum purity was $1.9 \mathrm{~m}^{3} / \mathrm{min}$. The average gas extraction purities of the four boreholes were $0.91 \mathrm{~m}^{3} / \mathrm{min}, 0.62 \mathrm{~m}^{3} / \mathrm{min}, 0.99 \mathrm{~m}^{3} / \mathrm{min}$, and $0.88 \mathrm{~m}^{3} / \mathrm{min}$.

The averaged absolute gas emission quantity on the working face is $9.79 \mathrm{~m}^{3} / \mathrm{min}$. When the gas extraction volume reached $1.95 \mathrm{~m}^{3} / \mathrm{min}$, it can meet the "provisional requirements for compliance of coal mine gas drainage," while the average total of the gas extraction volume of the four highlevel directional long boreholes is $3.42 \mathrm{~m}^{3} / \mathrm{min}$. Therefore, the construction locations of the high-level directional long boreholes were all in the gas enrichment area, and the overall drainage effect of the boreholes reached the expected effect.

5.2.2. Investigation on the Effect of Gas Governance. The change of the return airway corner and the return airflow gas concentration of the working face for the high-level directional long borehole extraction pressure relief gas of the goaf 


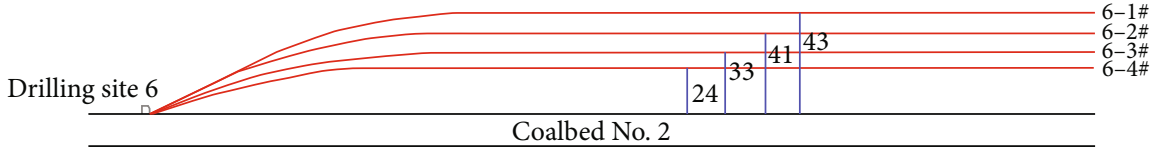

(a) Sectional drawing

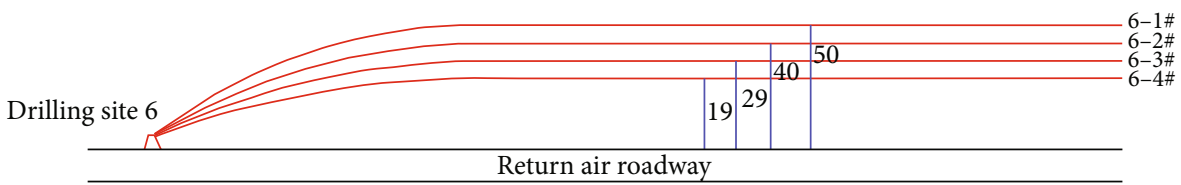

(b) Plain view drawing

Figure 11: High-level directional long drilling layout of the 6\# drilling site.

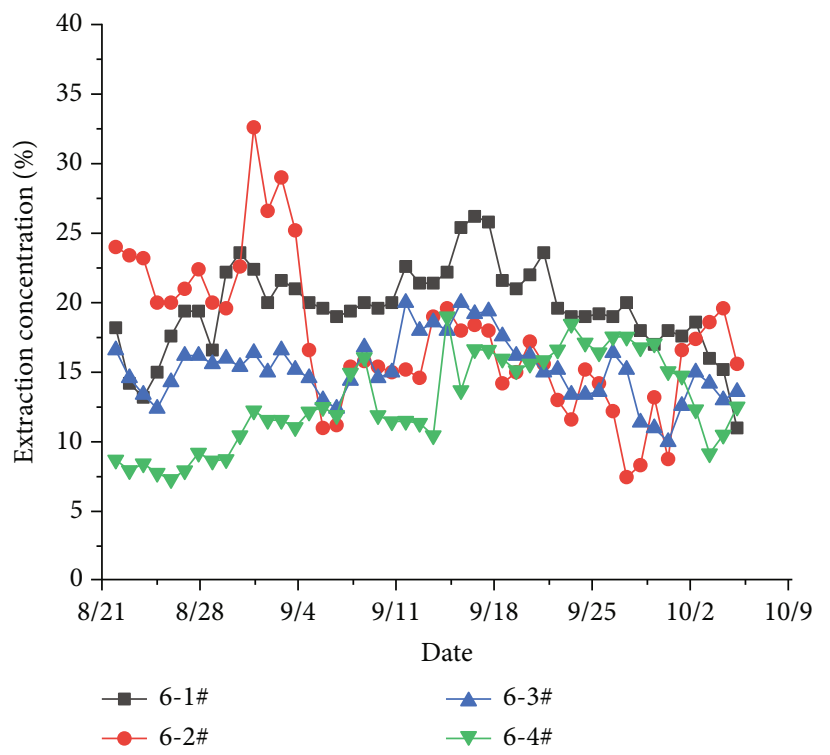

(a) Gas extraction concentration of the borehole

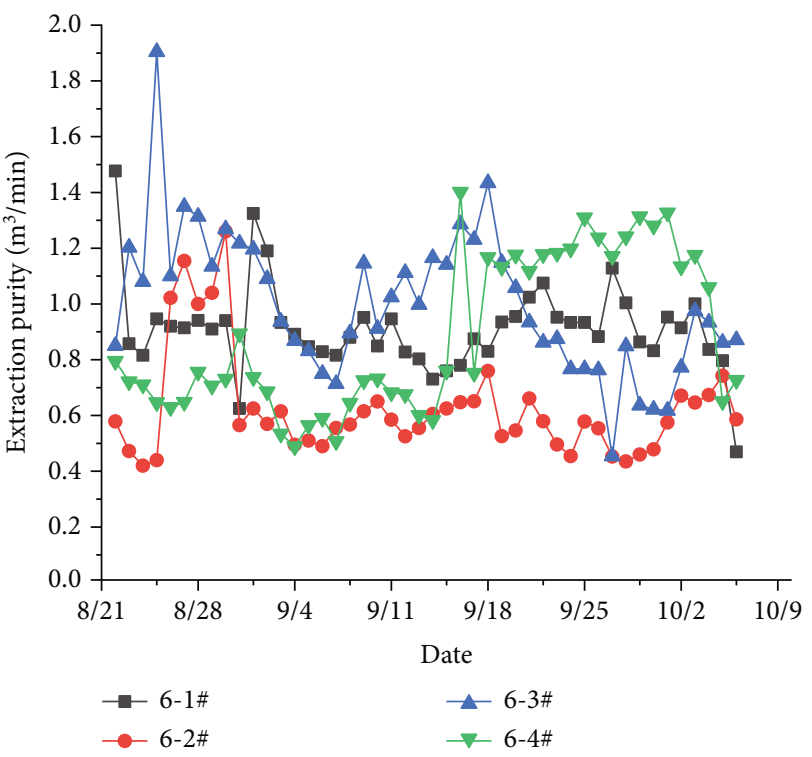

(b) Gas extraction purity of the borehole

FIgURE 12: Extraction effect of the high-level directional long borehole.

during the stable mining period of the working face is shown in Figure 13. Gas concentration in the return airway corner was between 0.30 and $0.49 \%$, whereas the gas concentration of return airflow was between $0.12 \%$ and $0.33 \%$.

According to regulations in Shanxi province, China, when the coal mine return airway corner and the return airflow methane concentration are greater than or equal to $0.8 \%$, the methane sensor will alarm. So the safety threshold of the return airway corner and return airflow gas concentration should be less than $0.8 \%$. The gas concentrations of the return airway corner and the working face are all below the safety threshold when the working face is normally mined, and high-level directional long boreholes are used to extract pressure relief gas.

\section{Discussion}

The gas migration behavior in goaf can be analyzed by exploring the law of fracture evolution of overlying strata caused by mining. This study used physical similarity simulation to explore gas migration. The fracture area distribution of the coal seam strike direction and inclined direction under the influence of mining was explored in this study. Physical test results were verified through an on-site drilling peep method.

The fracture area distribution of overlying strata was obtained using comparative on-site drilling peep and analogy simulation test results. The coal mining face was within $70 \mathrm{~m}$ of the return airway as a fracture area. After exceeding this area, it entered the compaction zone. The high fracture zone developed to about $100 \mathrm{~m}$ and entered the bending subsidence zone, and fissures were less developed.

Therefore, the distribution of the "three zones" of the overlying strata of the working face after mining was determined through comprehensive judgments. The $h_{2}$ which represents the final height of the caving zone was $28.2 \mathrm{~m}$, and the $h_{3}$ which is the development height of the fracture zone was $113.6 \mathrm{~m}$. In the strike direction, the $\beta_{2}$ of the caving angle in the inner part of the goaf after the coal seam was mined was $60^{\circ}$, and the $\beta_{1}$ of the caving angle in the location of the coal face was $52^{\circ}$. In the inclined direction, the $a_{1}$ of the caving angle on the side of the return airflow roadway was 


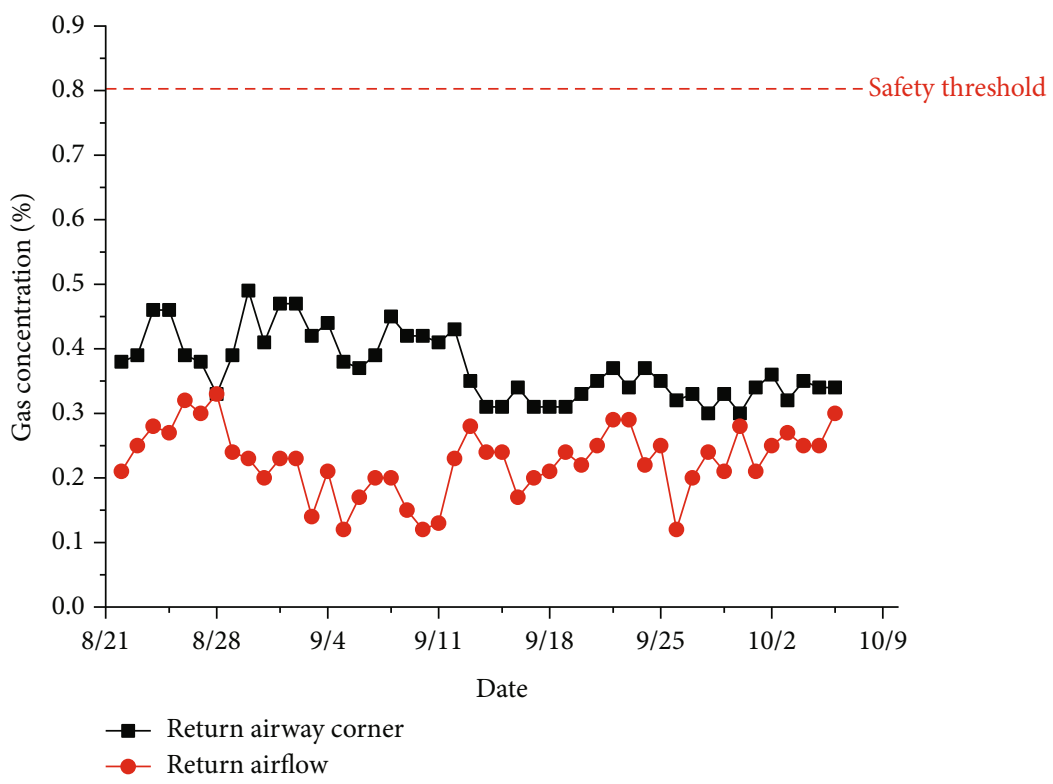

FIGURE 13: Return airway corner and return airflow gas concentration during mining.
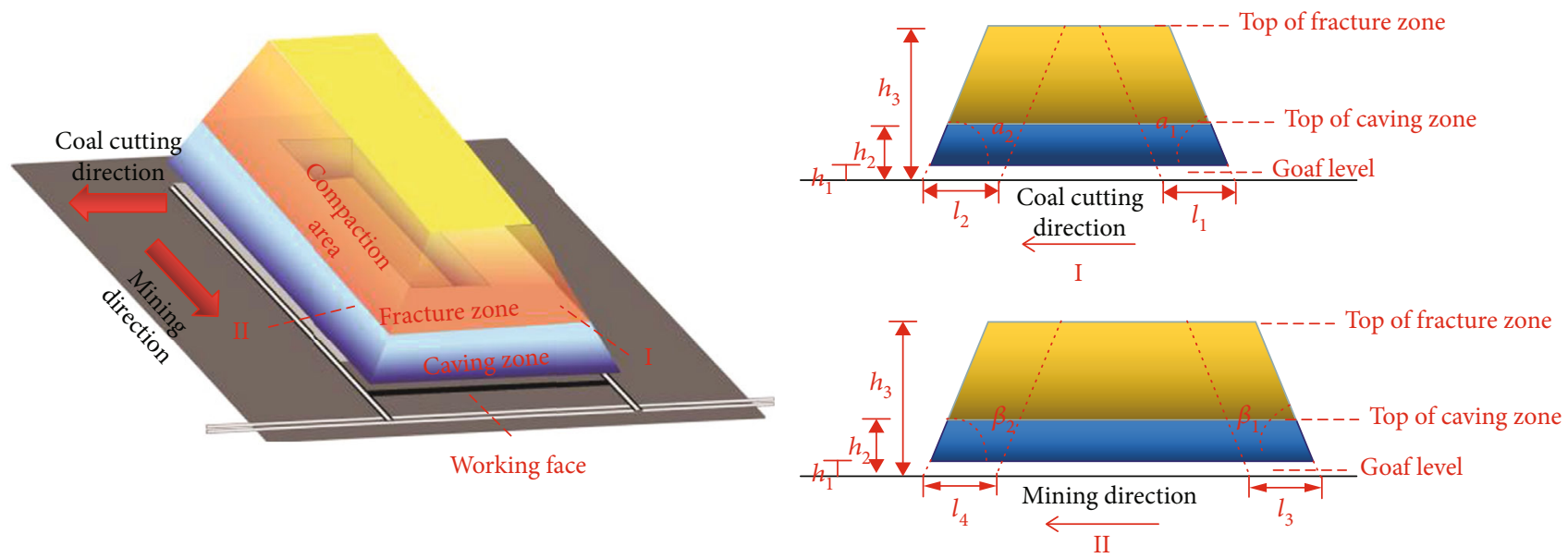

Figure 14: Distribution of the "three zones" of overlying strata under the influence of mining.

$63^{\circ}$, and the $a_{2}$ of the caving angle on the side of the intake airflow roadway was $56^{\circ}$. Analysis of the development of fractures after mining showed a vertical fracture development area above the top of the goaf, which was interpenetrated from the delamination fracture and vertical fracture. This fracture was directly connected to the area of the caving zone to form an "O"-type circle fracture zone [36] (Figure 14). A large number of delamination fractures and a small amount of penetrating fractures were formed in an "O"-type circle. After mining, the pressure relief gas moves and accumulates in this area, thus becoming the enrichment area of the pressure relief gas.

The different laws of gas emission of the coal wall, coal mine, and goaf were used to establish the dynamic emission models of different gas sources in goaf. The gas migration model of the working face and the goaf was established based on the law of gas migration. The gas migration model between the working face and the goaf was also established, which provides a basic algorithm to explore the law of the solid-gas coupling and gas migration in the fracture zone.

Further borehole peep results, gas emission models, and gas migration models based on physical analogy simulation test results were used to establish a numerical model of gas migration in goaf. The numerical model was used to test the gas migration in goaf. The gas migration law and distribution characteristics were obtained from quantitative analysis of the distribution of the gas enrichment area of overlying strata in goaf. The construction parameters of the high directional long borehole and the high-concentration gas area in the goaf overburden fracture zone were then used to control the gas in goaf. The gas emission in the mining period of the working face was effectively controlled, thus ensuring the safety production of the working face.

The aim of this systematic study was to explore the law of fracture evolution of overlying strata and the law of gas migration in goaf under fixed conditions. However, the law 
of the distribution of fracture of overlying strata and the gas emission in goaf under multiple disturbance conditions should be explored further. For instance, the law of the distribution of fracture of overlying strata in mining under the conditions of changes in mining speed, coal and rock properties, and faults should be determined. In addition, studies on the high-level drilling and buried pipe extraction in goaf and the gas migration law in goaf under the dynamic changes of the wind flow in goaf should be explored further to ensure the efficiency of gas control at the working face.

\section{Conclusion}

(1) A physical similarity experiment was used to simulate the distribution characteristics of the overlying strata fracture zone in goaf in the process of working face mining. Under the influence of mining, the fracture development of overlying strata in goaf is a "trapezoid platform structure," the maximum height of the caving zone is between $26 \mathrm{~m}$ and $28 \mathrm{~m}$, and the maximum height of the fracture zone is about $110 \mathrm{~m}$. Furthermore, the compaction area of goaf is located in the middle area of goaf, about $50 \mathrm{~m}$ away from the working face and approximately $22 \mathrm{~m}$ to $52 \mathrm{~m}$ away from the side of the return air roadway

(2) The mathematical model of dynamic gas emission in different states such as the coal wall, coal mine, and goaf was established based on the different forms of gas sources in the working face. The model was then used to establish the gas migration model in goaf. Moreover, the model was used to study the law of gas migration in the fracture of overlying strata in goaf under the influence of mining. Quantitative analysis of the gas distribution law at the $45 \mathrm{~m}$ depth of the goaf was carried out. The distribution law of the highest point of gas concentration at different heights was determined

(3) Reasonable high-location directional long borehole construction parameters were designed, and gas drainage in the goaf was carried out to ensure gas control in the fracture zone of the overlying strata in goaf. These processes can effectively solve the problem of high-concentration gas emission from the fracture zone of the overlying strata in goaf, thus effectively controlling the gas in the working face and the return airway corner. These processes ultimately improve mine gas control, thus ensuring safety production in mines

\section{Data Availability}

The data used to support the findings of this study are available from the corresponding author upon request.

\section{Conflicts of Interest}

The authors declare no conflicts of interest.

\section{Acknowledgments}

This research is financially supported by the National Natural Science Foundation of China (51874233, 51734007, and 51974241).

\section{References}

[1] Z. Wen, E. Xing, S. Shi, and Y. Jiang, "Overlying strata structural modeling and support applicability analysis for large mining-height stopes," Journal of Loss Prevention in the Process Industries, vol. 57, pp. 94-100, 2019.

[2] J. Ma, Q. Li, T. Kempka, and M. Kühn, "Hydromechanical response and impact of gas mixing behavior in subsurface CH4 storage with CO2-based cushion gas," Energy \& Fuels, vol. 33, no. 7, pp. 6527-6541, 2019.

[3] W. Kai and D. Feng, "Coal-gas compound dynamic disasters in China: a review," Process Safety and Environmental Protection, vol. 133, pp. 1-17, 2020.

[4] Y. Z. Shang, P. F. Hei, S. B. Lu et al., "China's energy-water nexus: assessing water conservation synergies of the total coal consumption cap strategy until 2050," Applied Energy, vol. 210, pp. 643-660, 2018.

[5] X. Y. Li, N. Zhang, Z. Z. Xie, D. X. Liang, and Y. M. Zhao, "Study on efficient utilization technology of coal pillar based on gob-side entry driving in a coal mine with great depth and high production," Sustainability, vol. 11, no. 6, 2019.

[6] Z. Liu, H. Yang, W. Cheng, L. Xin, and G. Ni, "Stress distribution characteristic analysis and control of coal and gas outburst disaster in a pressure-relief boundary area in protective layer mining," Arabian Journal of Geosciences, vol. 10, no. 16, p. 358, 2017.

[7] J. Brodny and M. Tutak, "Determination of the zone endangered by methane explosion in goaf with caving of longwalls ventilated on 'Y' system," Management Systems in Production Engineering, vol. 4, no. 24, pp. 247-251, 2016.

[8] J. Brodny, M. Tutak, and A. John, "Analysis of influence of types of rocks forming thegoaf with caving on the physical parameters of air stream flowing through these gob and adjacent headings," Mechanika, vol. 24, no. 1, pp. 43-49, 2017.

[9] L. Qin, P. Wang, S. Li et al., "Gas adsorption capacity of coal frozen with liquid nitrogen and variations in the proportions of the organic functional groups on the coal after freezing," Energy \& Fuels, vol. 35, no. 2, pp. 1404-1413, 2021.

[10] J. Cheng, X. Zhang, and A. Ghosh, "Explosion risk assessment model for underground mine atmosphere," Journal of Fire Sciences, vol. 35, no. 1, pp. 21-35, 2017.

[11] L. He, S. Yang, Q. Sun, T. Chen, and R. Huang, "Study on gas transportation principle and control in goaf with Y-shape ventilation system," Journal of Safety Science and Technology, vol. 7, no. 2, pp. 50-54, 2011.

[12] F. Wang, T. Ren, S. Tu, F. Hungerford, and N. Aziz, "Implementation of underground longhole directional drilling technology for greenhouse gas mitigation in Chinese coal mines," International Journal of Greenhouse Gas Control, vol. 11, pp. 290-303, 2012.

[13] F. Zhou, T. Xia, X. Wang, Y. Zhang, Y. Sun, and J. Liu, "Recent developments in coal mine methane extraction and utilization in China: a review," Journal of Natural Gas Science and Engineering, vol. 31, pp. 437-458, 2016. 
[14] Q. Qu, H. Guo, and M. Loney, "Analysis of longwall goaf gas drainage trials with surface directional boreholes," International Journal of Coal Geology, vol. 156, pp. 59-73, 2016.

[15] F. An, Z. Wang, H. Yang et al., "Application of directional boreholes for gas drainage of adjacent seams," International Journal of Rock Mechanics and Mining Sciences, vol. 90, pp. 35-42, 2016.

[16] D. Zhang, G. Fan, L. Ma, and X. Wang, “Aquifer protection during longwall mining of shallow coal seams: a case study in the Shendong Coalfield of China," International Journal of Coal Geology, vol. 86, no. 2-3, pp. 190-196, 2011.

[17] V. Palchik, "Influence of physical characteristics of weak rock mass on height of caved zone over abandoned subsurface coal mines," Environmental Geology, vol. 42, no. 1, pp. 92-101, 2002.

[18] V. Palchik, "Formation of fractured zones in overburden due to longwall mining," Environmental Geology, vol. 44, no. 1, pp. 28-38, 2003.

[19] A. Majdi, F. P. Hassani, and M. Y. Nasiri, "Prediction of the height of destressed zone above the mined panel roof in longwall coal mining," International Journal of Coal Geology, vol. 98, no. 1, pp. 62-72, 2012.

[20] H. Lin, S. Li, and L. Cheng, "Experimental analysis of dynamic evolution model of mining-induced fissure zone in overlying strata," Journal of Mining \& Safety Engineering, vol. 28, no. 2, pp. 298-303, 2011.

[21] J. Zhang and J. Wang, "Similar simulation and practical research on the mining overburden roof strata 'three-zone' height," Journal of Mining \& Safety Engineering, vol. 31, no. 2, pp. 249-254, 2014.

[22] F. Gao, D. Stead, and J. Coggan, "Evaluation of coal longwall caving characteristics using an innovative UDEC Trigon approach," Computers and Geotechnics, vol. 55, pp. 448-460, 2014.

[23] W. Wu, J. Bai, X. Wang, S. Yan, and S. Wu, "Numerical study of failure mechanisms and control techniques for a gob-side yield pillar in the Sijiazhuang coal mine, China," Rock Mechanics and Rock Engineering, vol. 52, no. 4, pp. 1231-1245, 2019.

[24] L. Yuan, "Scientific conception of precise coal mining," Journal of China Coal Society, vol. 42, no. 1, pp. 1-7, 2017.

[25] N. N. Danesh, Z. Chen, S. M. Aminossadati, M. S. Kizil, Z. Pan, and L. D. Connell, "Impact of creep on the evolution of coal permeability and gas drainage performance," Journal of Natural Gas Science \& Engineering, vol. 33, pp. 469-482, 2016.

[26] J. Cao and W. Li, "Numerical simulation of gas migration into mining-induced fracture network in the goaf," International Journal of Mining Science and Technology, vol. 27, no. 4, pp. 681-685, 2017.

[27] Y. Liu, S. Shao, X. Wang, L. Chang, G. Cui, and F. Zhou, "Gas flow analysis for the impact of gob gas ventholes on coalbed methane drainage from a longwall gob," Journal of Natural Gas Science and Engineering, vol. 36, pp. 1312-1325, 2016.

[28] D. N. Whittles, I. S. Lowndes, S. W. Kingman, C. Yates, and S. Jobling, "Influence of geotechnical factors on gas flow experienced in a UK longwall coal mine panel," International Journal of Rock Mechanics and Mining Sciences, vol. 43, no. 3, pp. 369-387, 2006.

[29] H. Guo, C. Todhunter, Q. Qu, and Z. Qin, "Longwall horizontal gas drainage through goaf pressure control," International Journal of Coal Geology, vol. 150-151, pp. 276-286, 2015.
[30] C. Zhang, S. Tu, Q. Bai, G. Yang, and L. Zhang, "Evaluating pressure-relief mining performances based on surface gas venthole extraction data in longwall coal mines," Journal of Natural Gas Science and Engineering, vol. 24, pp. 431-440, 2015.

[31] S. J. Schatzel, C. Ö. Karacan, H. Dougherty, and G. V. R. Goodman, "An analysis of reservoir conditions and responses in longwall panel overburden during mining and its effect on gob gas well performance," Engineering Geology, vol. 127, pp. 65-74, 2012.

[32] Y. Kang, J. Wang, and F. Kong, "Bore hole survey method for overburden failure," Coal Science and Technology, vol. 30, no. 12, pp. 26-28, 2002.

[33] W.-d. Wu, J.-b. Bai, X.-y. Wang, Z.-j. Zhu, and S. Yan, "Field investigation of fractures evolution in overlying strata caused by extraction of the Jurassic and Carboniferous coal seams and its application: case study," Case Study, International Journal of Coal Geology, vol. 208, pp. 12-23, 2019.

[34] D. Li, C. Xu, and Z. Xiong, "Gas flowing model of mining face and solve it using COMSOL," Journal of China Coal Society, vol. 37, no. 6, pp. 967-971, 2012.

[35] L. Zongxiang, S. Guangyi, and J. Wang, "Numerical simulation for non-homogeneous flow field and romantic movement law of gob," Chinese Journal of Rock Mechanics and Engineering, vol. 20, pp. 1578-1581, 2001.

[36] M. Qian and J. Xu, "Overburden fracture distribution of the 'O' shape of circle features," Journal of China Coal Society, vol. 23, no. 5, pp. 466-469, 1998. 